\title{
Potassium and Health ${ }^{1-3}$
}

\author{
Connie M. Weaver* \\ Department of Nutrition Science, Purdue University, West Lafayette, IN
}

\begin{abstract}
Potassium was identified as a shortfall nutrient by the Dietary Guidelines for Americans 2010 Advisory Committee. The committee concluded that there was a moderate body of evidence of the association between potassium intake and blood pressure reduction in adults, which in turn influences the risk of stroke and coronary heart disease. Evidence is also accumulating of the protective effect of adequate dietary potassium on age-related bone loss and reduction of kidney stones. These benefits depend on organic anions associated with potassium as occurs in foods such as fruits and vegetables, in contrast to similar blood pressure-lowering benefits of potassium chloride. Benefits to blood pressure and bone health may occur at levels below current recommendations for potassium intake, especially from diet, but dose-response trials are needed to confirm this. Nevertheless, intakes considerably above current levels are needed for optimal health, and studies evaluating small increases in fruit and vegetable intake on bone and heart outcomes for short periods have had disappointing results. In modern societies, Western diets have led to a decrease in potassium intake with reduced consumption of fruits and vegetables with a concomitant increase in sodium consumption through increased consumption of processed foods. Consumption of white vegetables is associated with decreased risk of stroke, possibly related to their high potassium content. Potatoes are the highest source of dietary potassium, but the addition of salt should be limited. Low potassium-to-sodium intake ratios are more strongly related to cardiovascular disease risk than either nutrient alone. This relationship deserves further attention for multiple target tissue endpoints. Adv. Nutr. 4: 368S-377S, 2013.
\end{abstract}

\section{Potassium is a shortfall nutrient}

Potassium is 1 of the 4 major shortfall nutrients in the American diet according to the 2010 Dietary Guidelines for American's Advisory Committee (1). Potassium requirements increased substantially in 2004 when the adequate intake was established at $4700 \mathrm{mg} / \mathrm{d}(2)$. It is difficult for most Americans to achieve these levels of intake. Only 3\% of Americans met the adequate intake in the 2003-2006 NHANES representative sample (3). The average potassium intake of Americans is just over half of the requirements at $2591 \pm 19 \mathrm{mg} / \mathrm{d}$.

'Published in a supplement to Advances in Nutrition. Presented at the Purdue University Roundtable on "White Vegetables: A Forgotten Source of Nutrients" held June 18-19, 2012 in Chicago, IL. The roundtable was sponsored by Purdue University. The roundtable and supplement publication were supported by an unrestricted grant from the Alliance for Potato Research and Education. All roundtable speakers received travel funding and an honorarium for participation in the meeting and manuscript preparation. The views expressed are those of the authors. The supplement coordinator was Catherine Nnoka, a paid consultant to the Alliance for Potato Research and Education. Guest editor Connie Weaver received compensation from the Alliance for Potato Research and Education for travel expenses, manuscript preparation, and editorial services for the supplement publication. Guest editor Cheryl Anderson received compensation from the Alliance for Potato Research and Education for editorial services.

${ }^{2}$ This article was supported by a grant from the Alliance for Potato Research and Education. ${ }^{3}$ Author disclosure: C. Weaver, member of the Scientific Advisory Board of Pharmavite.

* To whom correspondence should be addressed. E-mail: weavercm@purdue.edu.
Adequate dietary potassium is important for heart and bone health and reduces the risk of stroke and coronary heart disease. These relationships are the subject of this review. The effect of clinical hypokalemia on glucose intolerance, cardiac arrhythmias, and other consequences is not addressed here.

\section{Potassium and heart health}

The primary health outcome used to evaluate potassium intakes by the 2010 Dietary Guidelines for Americans Advisory Committee was blood pressure; other cardiovascular risks including stroke and coronary heart disease were also considered (1). However, the evidence of beneficial effects of potassium intake on the prevention of stroke and coronary heart disease was insufficient to guide dietary recommendations. Moreover, the benefits of dietary potassium may be primarily through its effect on blood pressure. High dietary potassium is associated with a decrease in blood pressure, particularly in the context of a high-sodium diet.

\section{Hypertension}

Hypertension is a major risk factor for the development of stroke, coronary heart disease, heart failure, and end-stage renal disease with a financial burden in the United States of $\$ 50.6$ billion in 2008 (4). Hypertension is the most common cause of death in the world (5) and is second only to 
smoking as a preventable cause of mortality in the United States. Approximately one third of U.S. adults had hypertension in the period 2005-2008 (4), with hypertension accounting for 1 in 6 deaths in U.S. adults in 2005. In fact, hypertension was the largest risk factor for cardiovascular mortality (45\% deaths) followed by overweight/obesity, physical inactivity, high LDL cholesterol, smoking, high dietary salt, and high trans fatty acids (6). With adults older than 50 y of age having a $90 \%$ lifetime risk of becoming hypertensive (7), it is not surprising that the total direct plus indirect cost of cardiovascular disease and stroke in the United States for 2008 was $\sim \$ 297.7$ billion with a prevalence of $\$ 82.6$ million for cardiovascular disease and $\$ 7$ million for stroke (4).

A substantial body of evidence has documented that in adults, as blood pressure increases, so does the risk of cardiovascular disease, particularly coronary heart disease and stroke, which together are the leading causes of mortality in the United States (4). Importantly, the relationship between blood pressure and subsequent events is direct and progressive throughout the range of blood pressure including the nonhypertensive ranges of blood pressure. It is well recognized that small changes in blood pressure can have substantial effects on mortality. In adults, a 2-mm Hg reduction in blood pressure can reduce mortality due to stroke by $6 \%$ and coronary heart disease by $4 \%(8)$.

Hypertension is one of the most modifiable risk factors in the development of cardiovascular disease, stroke, and chronic kidney disease aside from sodium reduction. Recently, severity of periodontal disease was also correlated with increased systolic and diastolic blood pressure and inversely correlated with urinary potassium excretion, reflective of low potassium intakes, in African women (9). Achieving adequate dietary potassium may be the most important dietary constituent in the tool box to lower blood pressure. Roger et al. (4), on behalf of the American Heart Association, estimated that increasing potassium intake would decrease the incidence of hypertension in Americans by $17 \%$ and would increase life expectancy by $5.1 \mathrm{y}$. A dietary intake of $>3500$ $\mathrm{mg} / \mathrm{d}$ is recommended for the primary prevention of hypertension (10).

The 2010 Dietary Guidelines for Americans Advisory Committee concluded that there was a moderate body of evidence of the association between potassium intake and blood pressure reduction in adults based on 36 clinical trials and 17 cohort studies reviewed by the 2005 Dietary Guidelines for Americans Advisory Committee (11) plus an additional 10 new studies (1). Five of these were systematic reviews and meta-analyses. Observational studies evaluated potassium from foods, whereas most trials used potassium supplements rather than food. However, the associated anion does not seem to affect blood pressure. The effect of potassium supplementation on blood pressure reduction is generally, but not consistently, positive. According to a Cochrane Database Systematic Review (12), potassium supplementation did not significantly reduce blood pressure in patients with hypertension. However, this meta-analysis only included 5 trials. In a meta-analysis of 19 supplement trials, potassium supplements significantly lowered systolic blood pressure by $5.9 \mathrm{~mm} \mathrm{Hg}$ and diastolic blood pressure by $3.4 \mathrm{~mm} \mathrm{Hg}$ (13). This effect size compares with 4 common monotherapy hypertensive drugs with effect sizes in the range of $6.9-9.3 \mathrm{~mm} \mathrm{Hg}(14)$. In a later meta-analysis of 33 randomized, controlled trials involving 2609 participants with normal blood pressure, potassium supplementation was associated with a significant mean reduction of $3.11 \mathrm{~mm} \mathrm{Hg}$ and $1.97 \mathrm{~mm} \mathrm{Hg}$ for systolic and diastolic blood pressure, respectively (15). Similarly, a fourth metaregression analysis reported that a potassium increase of $44 \mathrm{mmol} / \mathrm{d}$ resulted in a mean lowering of $2.4 \mathrm{~mm} \mathrm{Hg}$ and $1.5 \mathrm{~mm} \mathrm{Hg}$ for systolic and diastolic blood pressure, respectively (16). The blood pressure-lowering response of dietary potassium is greater in blacks than whites and in hypertensives than normotensives. Houston (17) graphed the results of the 4 meta analyses described to suggest a doseresponse effect of dietary potassium (Fig. 1). Nevertheless, a dose-response study would contribute greatly to the evidence of a dietary intake recommendation.

\section{Mechanisms of action}

Potassium has several purported mechanisms of action for its antihypertensive effects. Potassium decreases intravascular volume, partly through decreased sodium reabsorption, i.e., increased urinary sodium excretion. This effect does not persist so it cannot explain the long-term effects on blood pressure. Increased plasma potassium levels reflecting dietary intakes are associated with endothelium-dependent vasodilation via stimulation of the sodium-potassium adenosine triphosphatase pump and opening of potassium channels of the sodium-potassium adenosine triphosphatase pump (17). Houston (17) lists a number of other putative mechanisms of action for potassium including alterations in baroreflex sensitivity and sensitivity to receptors and hormones that influence vascular smooth muscle and

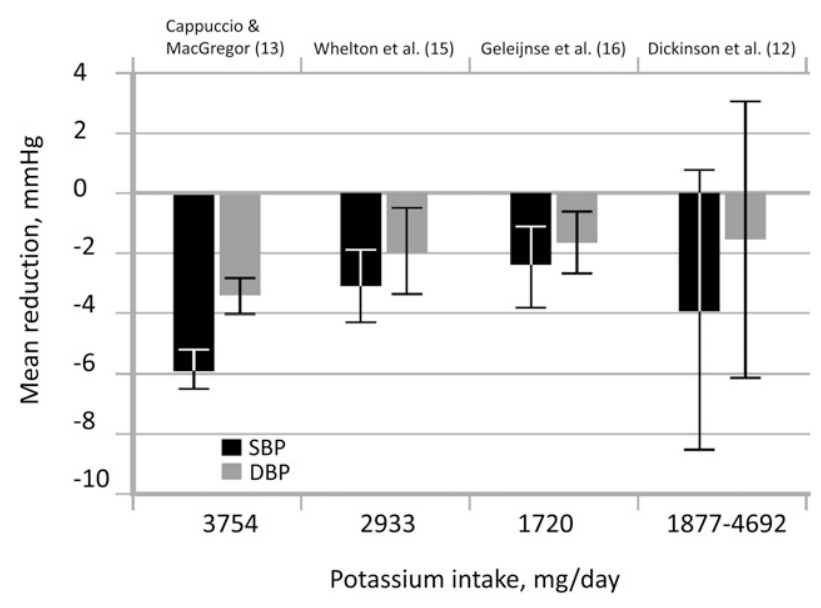

Figure 1 Overview of meta-analyses of studies investigating the mean blood pressure-lowering effects of potassium. DBP, diastolic blood pressure; SBP, systolic blood pressure. Reproduced from reference 17 with permission. 
sympathetic nervous system cell function. These effects may be important to lowering blood pressure in addition to the natriuretic effects of potassium.

\section{Potassium-sodium interaction}

The benefits of increased potassium and reduced sodium are incompletely additive, i.e., subadditive, meaning that individuals consuming high amounts of sodium may especially benefit from increasing potassium intakes. Also, the benefits of dietary potassium on blood pressure are strongest in saltsensitive individuals (1). Thus, dietary potassium and sodium should be considered together for benefits to blood pressure reduction.

The potassium:sodium intake ratio has decreased from early to modern times and differs between isolated and modern societies. Potassium intakes have decreased from 150 to $290 \mathrm{mmol} / \mathrm{d}$ to 30 to $70 \mathrm{mmol} / \mathrm{d}(6000-11,600$ to $1200-2800 \mathrm{mg} / \mathrm{d}$ ), whereas sodium increased from 20 to $40 \mathrm{mmol} / \mathrm{d}$ to 80 to $250 \mathrm{mmol} / \mathrm{d}$, leading to a shift in the dietary potassium:sodium ratio of $>3$ to $<0.4$ (17). Current recommendations for potassium $(4700 \mathrm{mg} / 117.5 \mathrm{mmol})$ and sodium $(2300 \mathrm{mg} / 100 \mathrm{mmol}$ or $1500 \mathrm{mg} / 65 \mathrm{mmol})$ intakes lead to molar ratios of 1.18 or 1.8. Achieving this intake ratio is a challenge with current eating patterns (18, 19). Nevertheless, data suggest that moving toward this goal has health benefits, especially in blacks who develop a salt sensitivity when even marginally deficient in potassium.

Higher potassium:sodium intakes (determined via urinary excretion rates) have stronger effects on blood pressure and the risk of subsequent cardiovascular disease than either sodium or potassium alone (20). The relationship was verified for both sexes and blacks (21). Using self-reported dietary intake data, Yang et al. (22) found lower potassium to sodium intake ratios strongly associated with increased allcause, cardiovascular, and ischemic heart disease (HRs of $1.46,1.46$, and 2.15 , respectively).

There is a limited number of clinical trials that simultaneously reduce sodium and increase potassium intake while controlling for potentially confounding dietary factors. In a small trial of 45 mildly hypertensive Finnish adults, a salt substitute containing $50 \%$ sodium chloride, $25 \%$ potassium chloride, and $25 \%$ magnesium ammonium potassium chloride reduced $(P<0.002)$ systolic blood pressure over $8 \mathrm{wk}$ compared with the control group $(-7.5$ vs. $+3.8 \mathrm{~mm} \mathrm{Hg})$ (23). In a study in Taiwanese veterans living in retirement homes, half of sodium chloride was replaced with potassium chloride in half of the kitchens (24). Cardiovascular diseaserelated mortality was significantly reduced (age-adjusted HR: 0.59; 95\% CI: 0.37-0.95) over 31 mo and medical expenses decreased by $\$ 426$ per year in the group receiving potassium salt.

\section{Potassium, stroke, and cardiovascular disease}

The dose-response relationship between dietary potassium and risk of stroke has been reported (25) (Fig. 2) . A 12-y prospective study showed that for every $10-\mathrm{mmol}$ increase in potassium intake per day, there was a $40 \%$ reduction in

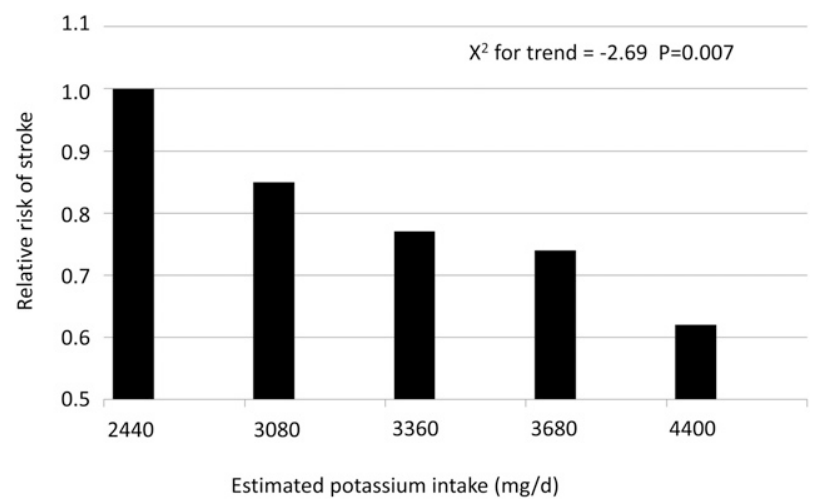

Figure 2 Effect of potassium citrate supplementation after 6 mo in older men and women on net renal acid excretion and calcium retention. Values are mean $\pm \mathrm{SE} ; N=52$. Data from reference 56.

stroke-associated mortality (26). Supportive of this finding was the observation that higher urinary potassium excretion in 28,880 patients with cardiovascular disease or diabetes was associated with reduced risk of stroke (27). A meta-analysis of 11 prospective studies of potassium intake, stroke, and cardiovascular disease involving $\sim 250,000$ individuals showed the strongest association with reduction of risk of stroke by $21 \%$ for every $1.64-\mathrm{g} / \mathrm{d}(423-\mathrm{mmol} / \mathrm{d})$ increase in potassium intake and a trend toward a lower risk of cardiovascular disease (28).

Much of the ability of dietary potassium to lower the risk of stroke is through its effect on lowering blood pressure (29). However, the effect persisted even when baseline blood pressure was accounted for, suggesting that additional mechanisms are at play (30). For example, potassium diets reduce free radical formation, but other bioactive constituents in fruits and vegetables likely have stronger antioxidant effects than potassium. Without changing blood pressure, 64 mmol of potassium, whether as the chloride or bicarbonate salt, improved endothelial function as measured by brachial artery flow-mediated dilation, increased arterial compliance as assessed by carotid-femoral pulse wave velocity, and reduced left ventricular mass and improved its function in 42 adults (31). These changes are predictive of cardiovascular morbidity and mortality. A higher urinary sodium:potassium ratio was associated with greater left ventricular mass in the CARDIA (Coronary Artery Risk Development in Young Adults) study independent of blood pressure (32). Additionally, a $4.5-\mathrm{g} / \mathrm{d}$ potassium chloride supplement ameliorated salt-induced hemostatic abnormalities linked to the risk of cardiovascular disease and stroke in rural Chinese (33).

The consumption of white fruits and vegetables has been evaluated in relation to stroke outcomes. In a large $10-y$ prospective Dutch population study including 20,069 men and women 20 to $65 \mathrm{y}$ of age, each $25 \mathrm{~g} / \mathrm{d}$ increase in consumption of white fruits and vegetables was associated with a $9 \%$ lower risk of stroke (HR: 0.91; 95\% CI: 0.85, 0.97) (34). This association was stronger than for total consumption of fruits and vegetables, and other categories of fruits and vegetables were not related to the incidence of stroke. This study adds a 
refinement to previous meta-analyses showing the benefit of fruit and vegetable consumption in reducing the risk of stroke $(35,36)$. The authors did not include potatoes in the white vegetable category; their inclusion may have led to even a stronger relationship.

\section{Potassium and bone health}

Dietary potassium may also benefit bone. The relationship of potassium and bone health has been studied through observational studies, controlled feeding studies, and randomized, controlled trials. The evidence of a benefit of potassium to bone is mixed, which may be due to methodological issues in studies such as the dose used, chemical form of potassium used, and other research methods. These issues are discussed here.

\section{Osteoporosis}

Osteoporosis is characterized by loss of bone mass with advanced age after peak bone mass and strength are established leading to skeletal fragility and fracture. More than 9 million fractures occur annually worldwide with an estimated cost of $\sim \$ 100$ billion (37).

Fragility fractures occur in individuals with low bone strength who experience an impact that exceeds bone strength such as occurs with a fall. Bone strength is determined by bone mineral density (BMD) ${ }^{4}$ as well as bone size and bone material properties. Bone is a living tissue that is constantly remodeling; bone is being resorbed, which releases mineral salts through action of osteoclasts, and bone is being formed to fill in the resorbed pits through the action of osteoblasts. Bone formation rates exceed bone resorption rates during growth, but ideally these 2 processes are in balance once peak bone mass is achieved in early adulthood. However, estrogen deficiency associated with menopause and aging results in accelerated bone resorption, which triggers increased bone formation rates as well, but often not sufficiently to maintain bone. When bone resorption rates exceed bone formation rates, bone balance is negative and net bone loss occurs. The rate of bone turnover depends not only on estrogen status but also on parathyroid hormone (PTH) levels, which increase in response to low dietary calcium to maintain serum calcium levels in the normal range. The extent to which this is necessary depends on dietary calcium levels. Bone turnover may also increase in response to acid. This also depends on diet (i.e., whether the diet is acidogenic). These dietary influences explain in part why as much as $40 \%$ of bone mass is determined by lifestyle choices, whereas genetics explain 60-80\% (38).

Studies on the effects of dietary potassium on bone strength and bone health have measured calcium homeostasis and retention, biochemical markers of bone turnover, or BMD.

\footnotetext{
${ }^{4}$ Abbreviations used: BMD, bone mineral density; DASH, Dietary Approaches to Stop

Hypertension; NRAE, net renal acid excretion; PTH, parathyroid hormone.
}

\section{Mechanisms for potassium benefits to bone}

The most promoted hypothesis for a bone benefit of dietary potassium is through its effect on acid-base balance, although the role of the skeleton in regulating $\mathrm{pH}$ is debated $(39,40)$. Homeostatic mechanisms keep systemic $\mathrm{pH}$ tightly controlled at between 7.35 and 7.45.

Those who support the acid-base theory postulate that the Western diet that is high in meats and cereal grains and low in fruits and vegetables creates a low-grade metabolic acidosis (39). Western diets lead to the production of 75 to $100 \mathrm{mEq}$ acid daily (39). This systemic state of lowgrade metabolic acidosis progressively worsens with age as renal function declines. Buffering of this acidic $\mathrm{pH}$ by the alkaline calcium salts in the skeleton would lead to bone loss. Accordingly, alkaline potassium salts produced from metabolizing fruits and vegetables or potassium supplements (potassium bicarbonate or citrate, but not potassium chloride) are thought to protect against bone resorption for $\mathrm{pH}$ homeostasis.

The following 2 mechanisms for the impact of acid excess on the skeleton have been proposed: $\mathrm{pH}$ buffered through skeleton acting as an ion-exchange column (39) and cellbased mechanism (i.e., osteoclasts, which resorb bone) (40). The first mechanism would occur rapidly and would not require cellular involvement.

Barzel (39) proposed that the hydration shell on the surface of bone has the capacity to release large amounts of sodium, carbonate, and citrate buffer to neutralize acid. The second mechanism would require a longer term response. Some (41) argue that the second mechanism is the only mechanism of bone resorption because bone mineral is not in direct contact with systemic circulation. Direct dissolution of bone mineral due to systemic acidosis is not necessary for bone resorption because extracellular $\mathrm{H}^{+}$can stimulate osteoclasts directly through interaction with a protein receptor (42), and this is in fact required for the initiation of osteoclast activity (40). The OGR7 receptor on osteoblasts sense acid levels, which induces intracellular $\mathrm{Ca}^{2+}$ release to mediate receptor activator of nuclear factor$\kappa \mathrm{B}$ ligand expression and therefore bone resorption (43).

Those who question the role of the skeleton to buffer excess acid mechanism argue that kidneys have the capacity to eliminate excess extracellular hydrogen ions generated by cellular metabolism (41). This begs the question that if dietary potassium does protect against bone loss, how would it do so if not through the acid-base mechanism? Is dietary potassium beneficial to bone only when renal function or the ability to generate ammonium is impaired? To answer this question, it helps to examine the strength of the evidence of a benefit of dietary potassium to bone.

\section{Results from observational studies of potassium and bone health}

High intake of fruits and vegetables have been associated with a benefit to bone health (44-46). Potassium levels in fruits and vegetables have been a leading candidate for this 
benefit. However, in a large Scottish study, flavonoid intake was more strongly related to bone than fruit and vegetable intake in general (47). Flavonoids are polyphenolic compounds, some of which have specific effects on osteoblasts (bone-forming cells) or osteoclasts (bone-resorbing cells) that reduce age-related bone loss (48). Observational studies have limited ability to distinguish the effect of potassium on bone in the context of many other constituents that may influence bone such as flavonoids.

\section{Potassium and the calcium economy}

Potassium intake has been associated with reduced urinary calcium excretion whether given as citrate or bicarbonate salts (49-51). Hypocalciuria persisted over $3 \mathrm{y}$ in men and women given 30,50 , or $90 \mathrm{mmol} / \mathrm{d}$ potassium bicarbonate (52). That potassium bicarbonate, but not sodium bicarbonate, reduced urinary calcium excretion in healthy men (50), and that potassium citrate, but not sodium citrate, reduced urinary calcium excretion in men with uric acid nephrolithiasis (53), suggest that potassium has a role beyond its alkalinization effect. The positive effect of potassium could be through either suppressing calcium resorption or bone mineral dissolution or both.

Although it had been assumed that the hypocalciuric effects of dietary potassium would result in improved calcium retention and, therefore, bone balance, results have varied. In a highly cited metabolic balance study, potassium supplementation did improve calcium balance (49). Postmenopausal women received 60 to $120 \mathrm{mmol} / \mathrm{d}$ potassium bicarbonate for $18 \mathrm{~d}$. Net renal acid excretion (NRAE) decreased from $70.9 \pm 10.1$ to $12.8 \pm 21.9 \mathrm{mmol} / \mathrm{d}$ and calcium balance increased by $56 \pm 76 \mathrm{mg} / \mathrm{d} / 60 \mathrm{~kg},(P=$ $0.009)$. In contrast, dietary potassium was not related to calcium balance in 191 women studied prospectively at 5-y intervals for 1 to 5 times (54). In this study, the investigators attempted to match self-selected diets of the participants during the 8-d balance studies. The 5th and 95th\% CI for potassium intake was 45.3 and $85.5 \mathrm{mmol} / \mathrm{d}$, respectively, and for renal NRAE, 29.8 and $65.5 \mathrm{mmol} / \mathrm{d}$, respectively. Because dietary potassium was not an intervention, intakes were lower and renal NRAE was much higher than in the Sebastian et al. (49) study, which used potassium bicarbonate supplementation. In the prospective balance study on habitual intakes (54), a negative relationship between dietary potassium and fractional calcium absorption was observed. The authors proposed that the hypocalciuric effect of dietary potassium was offset by reduced intestinal absorption. Because potassium reduces phosphate retention by the kidneys, renal calcitriol synthesis may be inhibited (55), which could explain reduced calcium absorption over time. Thus, within the range of habitual intakes of the study population, none of whom achieved their recommended intake of $4700 \mathrm{mg} / \mathrm{d}$ (median $<2500 \mathrm{mg} / \mathrm{d}$ ), dietary potassium had little apparent effect on calcium retention. More potassium came from meat and milk that are not metabolized to alkaline salts than from fruits and vegetables in the diets of the study participants. Thus, the benefit of potassium intake on bone was uncertain.

A recent randomized, double-blind, placebo-controlled trial shed new light on the discrepant findings of potassium intake and calcium retention (56). Six months of potassium citrate supplementation at 0,60 , or $90 \mathrm{mmol} / \mathrm{d}$ in $52 \mathrm{men}$ and women showed that $90 \mathrm{mmol} / \mathrm{d}$ was required to significantly improve calcium balance (Fig. 3). NRAE was reduced by nearly $30 \mathrm{mmol} / \mathrm{d}$ and urinary calcium by $9 \mathrm{mg} / \mathrm{d}$ compared with placebo with no change in fractional calcium absorption.

Taken altogether, these studies suggest that organic salts of potassium (such as occurs in fruits and vegetables) in doses sufficient to effectively neutralize NRAE can improve calcium balance. However, the mechanism remains unclear because the benefit of potassium salts may be independent of changes in NRAE.

\section{Bone turnover}

Several potassium supplementation trials have measured biochemical markers of bone turnover to investigate how potassium influences bone beyond its effect on calcium balance. Potassium bicarbonate at 60 to $120 \mathrm{mmol} / \mathrm{d}$ decreased urinary excretion of hydroxyproline, a marker of bone resorption, by $10 \%$ in postmenopausal women (49). Serum osteocalcin, a marker of bone formation, increased in the same study. Other studies have also shown that other biochemical markers of bone resorption, including $\mathrm{C}$ - and $\mathrm{N}$ telopeptide and procollagen type I N-terminal propeptide, decrease with potassium alkali treatment $(51,57)$. Similarly, serum C-telopeptide of type I collagen, a marker of bone resorption, decreased during 6 mo of treatment with both 60 and $90 \mathrm{mmol} / \mathrm{d}$ of potassium citrate, but, in contrast to

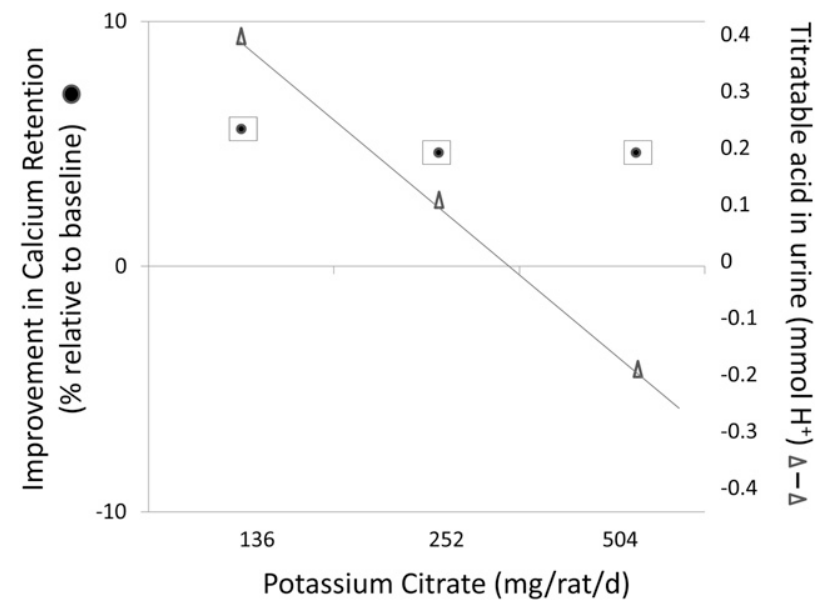

Figure 3 Potassium intake and adjusted risk of stroke among 43,738 U.S. men aged 40-75 y followed for 8 y. Risk was adjusted for age, total energy intake, smoking, alcohol consumption, history of hypertension, history of hypercholesterolemia, parental history of myocardial infarction before age $65 \mathrm{y}$, profession, and quintiles of BMI, and physical activity. Reproduced from reference 25 with permission. 
Sebastian et al. (49), serum bone-specific alkaline phosphatase, a marker of bone formation, did not increase (56).

Several lines of evidence challenge that acid-base balance is involved in bone turnover or the benefit of potassium in reducing bone turnover. Bisphosphonates are potent inhibitors of bone turnover. Yet, bisphosphonate treatment does not impair buffering of acids in those with healthy kidneys (58). This would suggest that the influence of acid-base balance is not essential to reducing bone resorption, nor is the alkaline load of fruits and vegetables essential to reducing bone resorption. In a rat model that measured bone turnover with high precision by monitoring urinary excretion tracer from prelabeled bone, addition of potassium citrate at levels that neutralized urinary titratable acid excretion from the acidogenic casein diet had no effect on bone turnover (Fig. 4) (59), nor did addition of potassium citrate affect the ability of onion or mixed vegetables to lower bone turnover. The authors suggested that bioactive compounds in the fruits and vegetables, including organic acids that could create more acidic ash, are responsible for benefits to bone.

The ability of flavonoids as the purported bioactive compounds in fruits and vegetables to reduce bone resorption rates and improve bone formation rates have been recently reviewed (48). However, it is not flavonoids that explain the benefit of potassium salts to bone health. Another observation inconsistent with acid loading causing increased urinary calcium is that adding potassium citrate to neutralize the acid load of a high protein diet did not reduce the hypercalciuria induced by the protein in healthy adults (60). In contrast, 50 or $70 \mathrm{mmol}$ potassium bicarbonate did reduce 3-h urinary calcium excretion acutely induced by moderate protein diets in adults in another study (61).

A plausible alternative hypothesis to the acid-base theory is that dietary organic salts of potassium lower circulating PTH levels. This would result in a reduction in urinary calcium excretion, thereby increasing calcium balance. In the

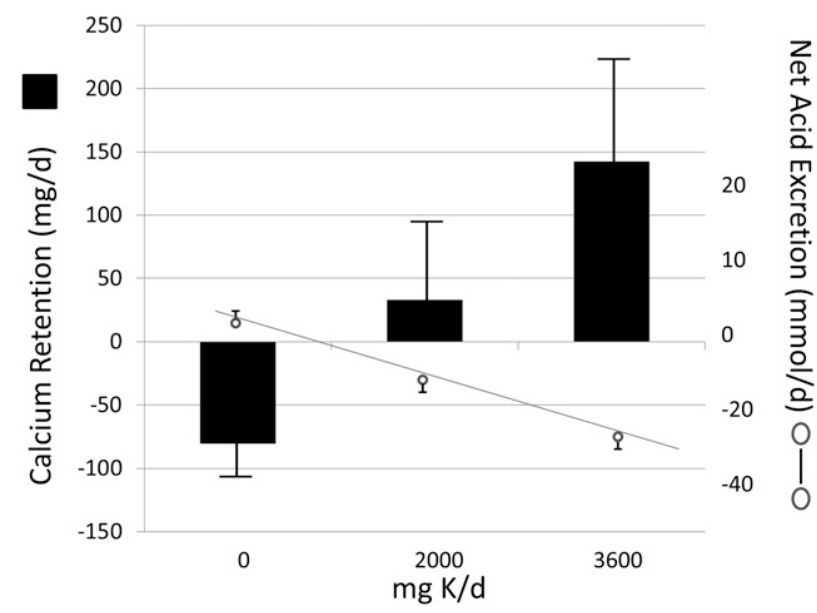

Figure 4 Potassium citrate at all levels significantly $(P<0.001)$ decreased mean 10- $d$ cumulative titratable acidity without affecting bone calcium retention (measured by urinary appearance of a bone tracer) in rats $(N=5)$. Data from reference 59 .
Moseley et al. (55) study, $90 \mathrm{mmol} / \mathrm{d}$ of potassium citrate decreased PTH significantly by $\sim 8 \mathrm{pg} / \mathrm{mL}$. However, this observation is not a consistent finding. Lower levels of $40 \mathrm{mmol}$ potassium citrate decreased urinary calcium with no changes in serum PTH, fractional calcium absorption, or bone resorption markers compared with a placebo in 18 postmenopausal women in a crossover study (62), nor were there differences in serum PTH with potassium bicarbonate supplementation compared with placebo (48-50).

The relationship of dietary potassium and bone is not clear from the biochemical marker data in the literature. Although the rate of bone turnover is 1 determinant of fracture risk, measures of bone turnover rates are generally used to gain insights on mechanisms. They are not as strong as imaging for assessing the impact of diet on bone density and strength.

\section{Potassium and BMD}

There are 3 trials of potassium and BMD. In the first trial, potassium citrate was compared with potassium chloride supplementation $(30 \mathrm{mEq} / \mathrm{d})$ for $1 \mathrm{y}$ in 161 postmenopausal women with low bone mass (63). A subset of women was measured for $\operatorname{NRAE}(\mathrm{mmol} / 24 \mathrm{~h})$ at $6 \pm 9$ and $35 \pm 8$ for the potassium citrate and potassium chloride groups, respectively. Potassium citrate was significantly more effective than potassium chloride in protecting against loss of BMD at the spine, femoral neck, and hip. Benefits (\% change in BMD) of potassium citrate over time compared favorably with the osteoporosis treatment drug raloxifene $(1.7 \%$ for raloxifene vs. $1.9 \%$ for potassium citrate at the lumbar spine), although it was less than for bisphosphonates (3.9\% for ibandronate) $(64,65)$. However, the lack of placebo in this study precludes knowing whether potassium citrate would provide benefit over no treatment. The authors assumed that bone loss in the women in the potassium citrate group was at a rate similar to those with no treatment, but if the women were not experiencing bone loss, the obvious interpretation would be that potassium chloride is detrimental to bone rather than potassium citrate is beneficial.

The second randomized, controlled trial compared potassium citrate $(55.5 \mathrm{mEq} / \mathrm{d}$ or $18.5 \mathrm{mEq} / \mathrm{d})$ and $300 \mathrm{~g}$ additional fruits and vegetables $(18.5 \mathrm{mEq}$ alkali/d) with a placebo group over 2 y in 276 postmenopausal women (66). The diet intervention was designed to have the same load as the lower potassium citrate group, but the types of fruits and vegetables were not controlled. The interventions had no benefit to BMD.

The third and strongest trial showed that 2 y of 60 $\mathrm{mmol} / \mathrm{d}(2400 \mathrm{mg} / \mathrm{d})$ potassium as potassium citrate improved BMD and bone microarchitecture in 201 elderly men and women (67). Spine BMD was increased $(P>$ 0.001 ) by $1.7 \pm 1.5 \%$ over the placebo, which correlated with changes in NRAE, and $1.6 \%$ at femoral neck. Tibial trabecular BMD increased $(P<0.001)$ by $1.3 \pm 1.3 \%$.

In summary, benefits of potassium on bone are seen typically when given as organic salts at relatively high doses of 60 to $90 \mathrm{mmol} / \mathrm{d}(2400-3600 \mathrm{mg} / \mathrm{d})$. Organic salts of 
potassium reduce urinary calcium loss and improve calcium balance at these levels. But whether that is related to protection against skeletal buffering of an acidogenic diet is still a topic for debate. Perhaps acid-base balance is not the mechanism in healthy kidneys, but as kidney function declined with age, it may be an important mechanism. The glomerular filtration rate declines by as much as $50 \%$ from age 20 to $80 \mathrm{y}$ (68), or perhaps excess acid only affects bone through interaction with receptors on bone cells to stimulate bone turnover, and this process is reduced by the alkaline organic salts of potassium.

\section{Potassium and the kidney}

The kidney regulates potassium homeostasis. Urinary excretion of excess potassium can reach $200 \mathrm{mmol} / \mathrm{d}$ unless $>90 \%$ of renal function is lost (68). Thus, a healthy kidney has great capacity to maintain potassium homeostasis in the face of excess potassium.

The renal hypercalciuria resulting from metabolic acidosis associated with consuming Western diets due to impairment of calcium reabsorption at the distal tubule increases the risk of kidney stones (69). Two observational U.S. studies showed that high intakes of potassium are associated with a reduction in recurrent kidney stones $(70,71)$ and 1 study in Finland showed no relationship (72). One U.S. study was a large 4-y prospective study of 45,619 adult men (69) and another a 12-y prospective study in women (70). Other studies have shown that supplementation with potassium citrate salts decreases stone recurrence (73-75). However, Maalouf et al. (60) concluded that the benefit of potassium citrate is not through the acid-base mechanism, but through correction of decreases in urine $\mathrm{pH}$ and citrate. In their crossover study of 11 healthy adults on controlled diets, potassium citrate protected against increased saturation of urine, with respect to calcium oxalate and urine acid, due to high protein diets. Lower urinary citrate and $\mathrm{pH}$ results in increased calcium oxalate saturation. Urinary citrate is a key inhibitor of nephrolithiasis, presumably by binding $\mathrm{Ca}^{2+}$ so that calcium oxalate formation is reduced. Both potassium citrate and bicarbonate, but not potassium chloride, increase urinary citrate (63). A higher $\mathrm{pH}$ favors formation of more soluble calcium salts over calcium oxalate.

Dietary potassium may slow progression of kidney disease. In hypertensive rats, high potassium intake prevents renal vascular, glomerular, and tubular damage independent of its effect on blood pressure (76). In a rat model of chronic kidney disease, potassium supplementation suppressed renal inflammation through upregulation of renal Smad 7 and downregulation of transforming growth factor $\beta$, both involved in the pathogenesis of progressive kidney injury (77). No controlled trials have been published that determine the role of dietary potassium and renal health in humans with hypertension or kidney disease.

\section{Dietary sources of potassium}

Potassium comes largely from fruits and vegetables (Table 1). The potato is the highest source of potassium of all foods. However, because of consumption patterns, the top potassium sources for Americans are milk, coffee, chicken and beef dishes, orange and grapefruit juice, and potatoes (Table 2). Potassium in foods is present with phosphate, sulfate, citrate, and many organic anions including proteins. Potassium intake decreased with the agricultural revolution when energy intake shifted from a variety of plants including potassium-rich tubers to cereals and animal products that have lower potassium concentrations and then further decreased with a shift to highly refined processed foods (69). Promoting nutrientrich foods to effect behavior modification is needed to increase potassium intake as well as other shortfall nutrients (78).

Table 1. Selected food sources ranked by amounts of potassium and energy per standard food portion

\begin{tabular}{|c|c|c|c|}
\hline Food & $\begin{array}{c}\text { Standard portion } \\
\text { size }\end{array}$ & $\begin{array}{l}\text { Energy in standard } \\
\text { portion }\end{array}$ & $\begin{array}{c}\text { Potassium in standard } \\
\text { portion }\end{array}$ \\
\hline & $g$ & kcal & $m g$ \\
\hline Potato, baked, flesh and skin & 1 small potato (143) & 128 & 738 \\
\hline Prune juice, canned & 1 cup (256) & 182 & 707 \\
\hline Carrot juice, canned & 1 cup (236) & 94 & 689 \\
\hline Tomato paste & $1 / 4$ cup (65.5) & 54 & 664 \\
\hline Beet greens, cooked & $1 / 2 \operatorname{cup}(74.5)$ & 19 & 654 \\
\hline White beans, canned & $1 / 2$ cup (90) & 149 & 595 \\
\hline Tomato juice, canned & 1 cup (243) & 41 & 556 \\
\hline Plain yogurt, nonfat or low fat & 8 oz (245) & $127-143$ & $531-579$ \\
\hline Tomato puree & $1 / 2$ cup (125) & 48 & 549 \\
\hline Sweet potato, baked in skin & 1 medium (119) & 103 & 542 \\
\hline Orange juice, fresh & 1 cup (248) & 112 & 496 \\
\hline Tuna, yellowfin, cooked & $3 \mathrm{oz}(57)$ & 118 & 484 \\
\hline Bananas & 1 medium (118) & 105 & 422 \\
\hline Skim milk & 1 cup (245) & 83 & 382 \\
\hline Parsnip, boiled & $1 / 2$ cup (80.5) & 55 & 296 \\
\hline Green peas, boiled & $1 / 2 \operatorname{cup}(82.5)$ & 37 & 217 \\
\hline Corn, boiled, sweet yellow & $1 / 2$ cup (79) & 72 & 162 \\
\hline Cauliflower, boiled & $1 / 2 \operatorname{cup}(70)$ & 14 & 89 \\
\hline
\end{tabular}

${ }^{1}$ Adapted from reference 1 with permission. 
Table 2. Daily potassium contribution of various foods among U.S. population, NHANES 2005-2006 ${ }^{1}$

\begin{tabular}{clcc}
\hline Rank & \multicolumn{1}{c}{ Food group } & & \\
\hline & & $\%$ & $m g$ \\
2 & Reduced fat milk & 5.9 & 154 \\
3 & Coffee & 5.2 & 135 \\
4 & Chicken and chicken mixed dishes & 4.5 & 119 \\
5 & Beef and beef mixed dishes & 3.6 & 94 \\
6 & 100\% orange/grapefruit juice & 3.4 & 90 \\
7 & Fried white potatoes & 3.3 & 87 \\
8 & Potato/corn/other chips & 3.2 & 83 \\
9 & Whole milk & 2.9 & 77 \\
10 & Other white potatoes & 2.9 & 75 \\
\hline
\end{tabular}

Adapted from reference 1 with permission.

\section{Dietary patterns}

Current strategies to increase potassium intakes recommend using foods instead of supplements (1). Even for patient populations, potassium supplements are not typically recommended, partly due to concern over hyperkalemia (77). The Dietary Approaches to Stop Hypertension (DASH)style diet represents a food-based approach to increasing potassium to levels recommended by the Institute of Medicine (2). The DASH diet is high in fruits and vegetables and dairy products and is effective at reducing blood pressure (79). Potassium content is thought to be the largest explanation of the benefit of this dietary pattern, although the increased level of magnesium, calcium, fiber, and other bioactive constituents may also contribute to lowering blood pressure.

The DASH diet reduced systolic and diastolic blood pressure in normotensives by 3.5 and $2.1 \mathrm{~mm} \mathrm{Hg}$, respectively, and 11.4 and $5.5 \mathrm{~mm} \mathrm{Hg}$, respectively, in hypertensives. Benefits were more pronounced in blacks and further benefits occurred with sodium reduction (80). Patients with stage 1 hypertension also experienced improved blood pressure control on a DASH diet plus sodium reduction (81). In addition to reducing blood pressure, a DASH diet intervention lowered biochemical markers of bone turnover (82) and DASH diet scores were associated with reduced risk of kidney stones, partly mediated by increased urinary citrate and volume (83).

Additionally, in 9585 Japanese hypertensive patients, potassium intake from fruits was associated with decreased systolic and diastolic blood pressure (84). In women, the lowest quartile of potassium intake was associated with a higher prevalence of metabolic syndrome as well. Dietary advice interventions aimed at increasing potassium intake by $\sim 20$ $\mathrm{mmol} / \mathrm{d}$ through fruits and vegetable intakes were successful in improving blood pressure in free-living individuals in the United States (85), but not in the United Kingdom (86). Differences in response in the 2 populations may be related to differences in baseline potassium intake, racial composition, or other subject characteristics.

\section{Conclusions}

Potassium is a shortfall nutrient that is not typically found in fortified foods or commonly consumed as dietary supplements. Fruits and vegetables, especially the potato, are excellent sources of potassium and play important roles in protecting against hypertension and, perhaps, in improving bone health. The organic potassium salts in foods have a broad range of health benefits to the heart, kidney, bone, and other tissues. Potassium chloride supplementation seemingly benefits blood pressure, but not bone. Clinical trials that are sufficiently large and of sufficiently long duration are needed for most of the health benefits attributed to potassium intake to establish causal relationships and dose response to guide public health decisions. Understanding the role of the skeleton in responding to metabolically produced acid excess and the hypocalciuric effects of potassium organic salts requires mechanistic studies. In patient populations, trials are needed to determine the effect of potassium intake on hypertensive renal disease. The inability to accurately assess dietary intakes makes it impossible to refine potassium recommendations from observational studies. Future trials may show that potassium benefits occur at intakes below the current recommendations of $4700 \mathrm{mg} / \mathrm{d}$. Evidence from trials on blood pressure suggests $3600-3800 \mathrm{mg} / \mathrm{d}$ may be reasonable for heart and bone health. This is still $1000 \mathrm{mg}$ higher than the current mean consumption of potassium. Improving the potassium:sodium intake ratio has a stronger advantage to heart health than either dietary constituent in isolation. This may be true for bone health also because these minerals have opposing actions on calcium excretion. Still, public health messages to improve diet quality generally has potential for more far-reaching impacts than encouraging single nutrients in isolation.

\section{Acknowledgments}

The sole author had responsibility for all parts of the manuscript.

\section{Literature Cited}

1. Dietary Guidelines Advisory Committee. Report of the Dietary Guidelines Advisory Committee on the Dietary Guidelines for Americans, 2010. Washington, DC: U.S. Department of Agriculture, Agricultural Research Service, 2011.

2. Food and Nutrition Board, Institute of Medicine. Sodium and chloride. Dietary reference intakes for water, potassium, sodium, chloride, and sulfate. Washington, DC: National Academies Press; 2005. p. 269-423.

3. Fulgoni VL III,, Keast DR, Bailey RL, Dwyer J. Food fortificants, and supplements: where do Americans get their nutrients? J Nutr. 2011; 141:1847-54.

4. Roger VL, Go AS, Lloyd-Jones DM, Benjamin EJ, Berry JD, Borden WB, Bravata DM, Dai S, Ford ES, Fox CS, et al., on behalf of the American Heart Association Statistics Committee and Stroke Statistics Subcommittee. Heart disease and stroke statistics - 2012 update: a report from the American Heart Association. Circulation. 2012;125: e2-220.

5. Lopez AD, Mathers CD, Ezzati M, Jamison DT, Murray CJ. Global and regional burden of disease and risk factors, 2001: systematic analysis of population health data. Lancet. 2006;367:1747-57.

6. Danaei G, Ding EL, Mozaffarian D, Taylor B, Rehm J, Murray CJ, Ezzati M. The preventable causes of death in the United States: comparative risk assessment of dietary, lifestyle, and metabolic risk factors. PLoS Med. 2009;6:e1000058.

7. Vasan RS, Beiser A, Seshadri S, Larson MG, Kannel WB, D’Agostino RB, Levy D. Residual lifetime risk for developing hypertension in middle- 
aged women and men: the Framingham Heart Study. JAMA. 2002;287: 1003-10.

8. Stampfler R. Implications of the INTERSALT study. Hypertension. 1991;77:I16-20.

9. Yamori M, Njelekela M, Mtabaji J, Yamori Y, Bessho K. Hypertension, periodontal disease, and potassium intake in nonsmoking, nondrinker African women on no medication. Int J Hypertens. 2011;2011: .

10. Chobanian AV, Bakris GL, Black HR, Cushman WC, Green LA, Izzo JL, Jr., Jones DW, Materson BJ, Oparil S, Wright JT Jr, et al. the National High Blood Pressure Education Program Coordinating Committee. The Seventh Report of the Joint National Committee on Prevention, Detection, Evaluation, and Treatment of High Blood Pressure: The JNC 7 report. JAMA. 2003;289:2560-72.

11. Dietary Guidelines Advisory Committee. Report of the Dietary Guidelines Advisory Committee on the Dietary Guidelines for Americans, 2005. Washington, DC: U.S. Department of Agriculture, Agricultural Research Service, 2004.

12. Dickinson HO, Nicolson D, Campbell F, Beyer FR, Mason J. Potassium supplementation for the management of primary hypertension in adults. Cochrane Database Syst Rev..2006;(3):CD004641.

13. Cappuccio FP, MacGregor GA. Does potassium supplementation lower blood pressure? A meta-analysis of published trials. J Hypertens. 1991; 9:465-73.

14. Wald DS, Law M, Morris JK, Bestwick JP, Wald NJ. Combination therapy versus monotherapy in reducing blood pressure: meta-analysis on 11,000 participants from 42 trials. Am J Med. 2009;122:290-300.

15. Whelton PK, He J, Cutler JA, Brancati FL, Appel LJ, Follman D, Klag MJ. Effect of oral potassium on blood pressure. JAMA. 1997;277: 1624-32.

16. Geleijnse JM, Kok FJ, Grabbee DE. Blood pressure response to changes in sodium and potassium intake: a metaregression analysis of randomised trials. J Hum Hypertens. 2003;17:471-80.

17. Houston MC. The importance of potassium in managing hypertension. Curr Hypertens Rep. 2011;13:309-17.

18. Drewnowski A, Maillot M, Rehm C. Reducing the sodium-potassium ratio in the U.S. diet: a challenge for public health. Am J Clin Nutr. 2012;96:439-44.

19. Donfrancesco C, Ippolito R, Lo Noce C, Palmieri L, Iacone R, Russo O, Vanuzzo D, Galletti F, Galeone D, Giampaoli S, et al. Excess dietary sodium and inadequate potassium intake in Italy: results of the MINISAL study. Nutr Metab Cardiovasc Dis. Epub 2012 Jul 24.

20. Cook NR, Obarzanek E, Cutler JA, Buring JE, Rexrode KM, Kumanyika SK, Appel LJ, Whelton PK.; for the Trials of Hypertension Prevention Collaborative Research Group. Joint effects of sodium and potassium intake on subsequent cardiovascular disease. Arch Intern Med. 2009; 169:32-40.

21. Hedayati SS, Minhajuddin AT, Ijaz A, Moe OW, Elsayed EF, Reilly RF, Huang CL. Association of urinary sodium/potassium ratio with blood pressure: sex and racial differences. Clin J Am Soc Nephrol. 2012;7: $315-22$.

22. Yang Q, Liu T, Kuklina EV, Flanders WD, Hong Y, Gillespie C, Chang MH, Gwinn M, Dowling N, Khoury MJ, et al. Sodium and potassium intake and mortality among U.S. adults: prospective data from the Third National Health and Examination Survey. Arch Intern Med. 2011;171:1183-91.

23. Sarkkinen ES, Kastarinen MJ, Niskanen TH, Karjalainen $\mathrm{PH}$, Venäläinen TM, Udani JK, Niskanen LK. Feasibility and antihypertension effect of replacing regular salt with mineral salt-rich in magnesium and potassium- in subjects with mildly evaluated blood pressure. Nutr J. 2011;10:88.

24. Chang H-Y, Hu Y-W, Yue C-SJ, Wen Y-W, Yeh W-T, Hsu L-S, Tsai S-Y, Pan W-H. Effect of potassium-enriched salt on cardiovascular mortality and medical expenses of elderly men. Am J Clin Nutr. 2006; 83:1289-96.

25. He FJ, MacGregor GA. Fortnightly review: Beneficial effects of potassium. BMJ. 2001;323:497-501.

26. Khaw KT, Barrett-Conner E. Dietary potassium and stroke-associated mortality: A 12-year prospective study. N Engl J Med. 1987;316:235-40.
27. O’Donnell MJ, Yusuf S, Mente A, Gao P, Mann JF, Teo K, McQueen M, Sleight P, Sharma AM, Dans A, et al. Urinary sodium and potassium excretion and risk of cardiovascular events. JAMA. 2011;306:2229-38.

28. D’Elia L, Barba G, Cappuccio FP, Strazzullo P. Potassium intake, stroke, and cardiovascular disease. A meta-analysis of prospective studies. J Am Coll Cardiol. 2011;57:1210-9.

29. Kido M, Ando K, Onozato ML, Tojo A, Yoshikawa M, Ogita T, Fujita T. Protective effect of dietary potassium against vascular injury in saltsensitive hypertension. Hypertension. 2008;51:225-31.

30. He FJ, Marciniak M, Carney C, Markandu ND, Anand V, Fraser WD, Dalton RN, Kaski JC, MacGregor GA. Effects of potassium chloride and potassium bicarbonate on endothelial function, cardiovascular risk factors, and bone turnover in mild hypertensives. Hypertension. 2010;55:681-8.

31. Levy D, Garrison RJ, Savage DD, Kannel WB, Castelli WP. Prognostic implications of echocardiographically determined left ventricular mass in the Framingham Heart Study. N Engl J Med. 1990;322:1561-6.

32. Rodriguez CJ, Bibbins-Domingo K, Jin Z, Daviglus ML, Goff DC, Jr., Jacobs DR, Jr. Association of sodium and potassium intake with left ventricular mass: Coronary artery risk development in young adults. Hypertension. 2011;58:410-6.

33. Liu F, Mu J, Yuan Z, Zhang M, Zheng S, Lian Q, Liu E, Xu H, Ren K, Huang Q. Potassium supplement ameliorates salt-induced haemostatic abnormalities in normotensive subjects. Acta Cardiol. 2011;66:635-39.

34. Oude Griep LM, Verschuren WMM, Kromhout D, Ocké MC, Geleijnse JM. Colors of fruits and vegetables and 10-year incidence of stroke. Stroke. 2011;42:3190-5.

35. Dauchet L, Amouyel P, Dallongeville J. Fruit and vegetable consumption and risk of stroke: a meta-analysis of cohort studies. Neurology. 2005;65:1193-7.

36. He FJ, Nowson CA, MacGregor GA. Fruit and vegetable consumption and stroke: meta-analysis of cohort studies. Lancet. 2006;367:320-6.

37. Compston J. Osteoporosis: social and economic impact. Radiol Clin North Am. 2010;48:477-82.

38. Seeman E, Hopper JL, Young NR, Formica C, Goss P, Tsalamandris C. Do genetic factors explain associations between muscle, strength, lean mass, and bone density? A twin study. Am J Physiol. 1996;270:E320-7.

39. Barzel US. The skeleton as an ion exchange system: Implications for the role of acid-base imbalance in the genesis of osteoporosis. J Bone Miner Res. 1995;10:1431-6.

40. Arnett TR. Acid-base regulation of bone metabolism. In: Burckhardt P, Heaney RP, Dawson-Hughes B, eds. Nutritional aspects of osteoporosis. New York: Elsevier; 2007. p. 255-67.

41. Bonjour J-P. Dietary protein: an essential nutrient for bone health. J Am Coll Nutr. 2005;24:526S-36S

42. Komarova SV, Pereverzev A, Shum JW, Sims SM, Dixon SJ. Convergent signaling by acidosis and receptor activator of NF-Kappa B ligand (RANKL) on the calcium/calcineurin/NFAT pathway in osteoclasts. Proc Natl Acad Sci U S A. 2005;102:2643-8.

43. Dawson-Hughes B. Acid-base balance, bone, and muscle. In: Burckhardt P, Dawson Hughes B, Weaver CM, eds. Nutritional influences on bone health. London: Springer-Verlag; , 2010. p. 173-9.

44. Tucker KL, Hannan MT, Chen H, Cupples LA, Wilson PW, Keil DP. Potassium, magnesium and fruit and vegetable intakes are associated with greater bone mineral density in elderly men and women. Am J Clin Nutr. 1999;69:727-36.

45. Prynne CJ, Mishra GD, O'Connell MA, Muniz G, Laskey MA, Yan L, Prentice A, Ginty F. Fruit and vegetable intakes and bone mineral status: a cross-sectional study in 5 age and sex cohorts. Am J Clin Nutr. 2006;83:1420-8

46. Chen Y-M, Ho SC, Woo JL. Greater fruit and vegetable intake is associated with increase bone mass among postmenopausal Chinese women. Br J Nutr. 2006;96:745-51.

47. Hardcastle AC, Aucott L, Reid DM, Macdonald HM. Associations between dietary flavonoid intakes and bone health in a Scottish population. J Bone Miner Res. 2011;26:941-7.

48. Weaver CM, Alekel DL, Ward WE, Ronis MJ. Flavonoid intake and bone health. J Nutr Gerontol Geriatr. 2012;31:239-53. 
49. Sebastian A, Harris St, Ottaway JH, Todd KM, Morris RC, Jr. Improved mineral balance and skeletal metabolism in postmenopausal women treated with potassium bicarbonate. N Engl J Med. 1994;330:1776-81.

50. Lemann J, Gray RW, Pleuss JA. Potassium bicarbonate, but not sodium bicarbonate, reduces urinary calcium excretion and improves calcium balance in healthy men. Kidney Int. 1989;35:688-95.

51. Dawson-Hughes B, Harris SS, Palermo NJ. Treatment with potassium bicarbonate lowers calcium excretion and bone resorption in older men and women. J Clin Endocrinol Metab. 2009;94:96-102.

52. Frassetto L, Morris RC Jr, Sebastian A. Long-term persistence of the urine calcium-lowering effect of potassium bicarbonate in postmenopausal women. J Clin Endocrinol Metab. 2005;90:831-4.

53. Sakhaee K, Nicar M, Hill K, Pak CY. Contrasting effects of potassium citrate and sodium citrate therapies on urinary chemistry and crystallization of stone-forming salts. Kidney Int. 1983;24:348-52.

54. Rafferty K, Davies KM, Heaney RP. Potassium intake and the calcium economy. J Am Coll Nutr. 2005;24:99-106.

55. Lemann J, Pleuss JA, Gray RW. Potassium causes calcium retention in healthy adults. J Nutr. 1993;123:1623-6.

56. Moseley K, Weaver C, Appel L, Sebastian A, Sellmeyer DE. Potassium citrate supplementation results in sustained improvement in calcium balance in older men and women. J Bone Miner Res. Epub 2012 Sep 18.

57. Marangella M, DiStefano M, Casalis S, Berutti S, D'Amelio P, Isaia GC. Effects of potassium citrate supplementation on bone metabolism. Calcif Tissue Int. 2004;74:330-5.

58. Freudiger H, Bonjour JP. Bisphosphonates and extrarenal acid buffering capacity. Calcif Tissue Int. 1989;44:3-10.

59. Mühlbauer RC, Lozano A, Reinli A. Onion and a mixture of vegetables, salads, and herbs affect bone resorption in the rate by a mechanism independent of their base excess. J Bone Miner Res. 2002;17: $1230-6$.

60. Maalouf NM, Moe OW, Adams-Huet B, Sakahee K. Hypercalciuria associated with high dietary protein intake is not due to acid load. J Clin Endocrinol Metab. 2011;96:3733-40.

61. Whiting SJ, Anderson DJ, Weeks SJ. Calciuric effects of protein and potassium bicarbonate but not of sodium chloride a phosphate can be detected acutely in adult women and men. Am J Clin Nutr. 1997;65: 1465-72.

62. Sakhaee K, Alpern R, Jacobson HR, Pak CYC. Contrasting effects of various potassium salts on renal citrate excretion. J Clin Endocrinol Metab. 1991;72:396-400.

63. Jehle S, Zanetti A, Muser J, Hulter HN, Krapf R. Partial neutralization of the acidogenic Western diet with potassium citrate increases bone mass in postmenopausal women with Osteopenia. J Am Soc Nephrol. 2006;17:3213-22.

64. Delmas PD, Bjarnason NH, Mitlak BH, Ravoux AC, Shah AS, Huster WJ, Draper M, Christiansen C. Effects of raloxifene on bone mineral density, serum cholesterol concentrations, and uterine endometrium in postmenopausal women. N Engl J Med. 1997;337:1641-47.

65. Ravn P, Clemmesen B, Riis BJ, Christiansen C. The effect on bone mass and bone markers of different doses of ibandronate: a new bisphosphonate for prevention and treatment of postmenpausal osteoporosis-A 1-year, randomized, double-blind, placebo-controlled dose-finding study. Bone. 1996;19:527-33.

66. Macdonald HM, Black AJ, Aucott L, Duthie G, Duthie S, Sandison R, Hardcastle AC, Lanham New SA, Fraser WD, Reid DM. Effect of potassium citrate supplementation or increased fruit and vegetable intake on bone metabolism in healthy postmenopausal women: a randomized controlled trial. Am J Clin Nutr. 2008;88:465-74.

67. Jehle S, Hutler HN, Krapf R. Effect of potassium citrate on bone density, microarchitecture, and fracture risk in healthy older adults without osteoporosis: a randomized controlled trial. J Clin Endocrinol Metab. 2013;98:207-17.
68. Rowe JW, Andres R, Tobin JD, Norris AH, Shock NW. The effect of age on creatinine clearance in men: a cross-sectional and longitudinal study. J Gerontol. 1976;31:155-63.

69. He FJ, MacGregor GA. Beneficial effects of potassium on human health. Physiol Plant. 2008;133:725-35.

70. Curhan GC, Willett WC, Rimm EB, Stampfer MJ. A prospective study of dietary calcium and other nutrients and the risk of symptomatic kidney stones. N Engl J Med. 1993;328:833-8.

71. Curhan GC, Willett WC, Speizer FE, Spiegelman D. Comparison of dietary calcium with supplemented calcium and other nutrients as factors affecting risk of kidney stones in women. Ann Intern Med. 1997;126: 497-504.

72. Hirvonen T, Pietinen P, Virtanen M, Albanes D, Virtamo J. Nutrient intake and use of beverages and the risk of kidney stones among male smokers. Am J Epidemiol. 1999;150:187-94.

73. Ettinger B, Pak CY, Citron JT, Thomas C, Adams-Huet B, Vangessel A. Potassium-magnesium citrate is an effective prophylaxis against recurrent calcium oxalate nephrolithiasis. J Urol. 1997;158:2069-73.

74. Barcelo P, Wuhl O, Sevitge E, Rousand A, Pak CYC. Randomized double-blind study of potassium citrate in idiopathic calcium nephrolithiasis. J Urol. 1993;150:1761-4.

75. Zerwekh JE, Odvina CV, Wuermser LA, Pak CY. Reduction of renal stone risk by potassium-magnesium citrate during 5 weeks of bed rest. J Urol. 2007;2179-84.

76. Tobian L, MacNeill D, Johnson MA, Ganguli MC, Iwai J. Potassium protection against lesions of the renal tubules, arteries, and glomeruli and nephron loss in salt-loaded hypertensive Dahl S rats. Hypertension. 1984;6:I170-6.

77. Wang W, Soltero L, Zhang D, Huang XR, Lan HY, Adrogue HJ. Renal inflammation is modulated by potassium in chronic kidney disease: possible role of Smad 7. Am J Physiol Renal Physiol. 2007;293:F1123-30.

78. Drewnowski A, Fulgoni, III V. Comparing the nutrient rich foods index with "Go", "Slow", and "Whoa" foods. J Am Diet Assoc. 2011;111:280-4.

79. Appel LJ, Moore TJ, Obarzanek E, Vollmer WM, Svetkey LP, Sacks FM, Bray GA, Vogt TM, Cutler JA, Windhauser MM, et al. A clinical trial of the effects of dietary patterns on blood pressure. DASH Collaborative Research Group. N Engl J Med. 1997;336:1117-24.

80. Sacks FM, Svetkey LP, Vollmer WM, Appel LJ, Bray GA, Harsha D, Obarzanek E, Conlin PR, Miller ER, Simons-Morton D, et al., DASH Sodium Collaborative Research Group. Effects on blood pressure of reduced dietary sodium and the Dietary Approaches to Stop Hypertension (DASH) diet. N Engl J Med. 2001;344:3-10.

81. Svetkey LP, Simons-Morton DG, Proschan MA, Sacks FM, Conlin PR, Harsha D, Moore TJ. Effect of the dietary approaches to stop hypertension diet and reduced sodium intake on blood pressure control. J Clin Hypertens (Greenwich). 2004;6:373-81.

82. Lin PH, Genty F, Appel LJ, Aickin M, Bohannon A, Garnero P, Barclay D, Svetkey LP. The DASH diet and sodium reduction improve markers of bone turnover and calcium metabolism in adults. J Nutr. 2003;133: $3130-6$.

83. Taylor EN, Stampfer MJ, Mount DB, Curhan GC. DASH-style diet and 24-hour composition. Clin J Am Soc Nephrol. 2010;5:2315-22.

84. Teramoto T, Kawamori R, Miyazaki S, Teramukai S., for the OMEGA Study Group. Sodium intake in men and potassium intake in women determine the prevalence of metabolic syndrome in Japanese hypertensive patients: OMEGA Study. Hypertens Res. 2011;34:957-62.

85. Appel LJ, Champagne CM, Harsha DW, Cooper LS, Obarzanek E, Elmer PJ, Stevens VJ, Vollmer WM, Lin PH, Svetkey LP, et al., Writing Group of the PREMEIER Collaborative Research GroupEffects of comprehensive lifestyle modifications on blood pressure control: main results of the PREMIER clinical trial. JAMA. 2003;289:2083-93.

86. Berry SE, Mulla UZ, Chowienczyk PJ, Sanders TA. Increased potassium intake from fruit and vegetables or supplements does not lower blood pressure or improve vascular function in UK men and women with early hypertension: a randomised controlled diet. Br J Nutr. 2010;104:1839-47. 